\title{
Studies on the anti-parasitic efficacy and safety of ivermectin and pyrantel pamoate compound against Dirofilaria immitis in dogs
}

\author{
Heejeong Youn ${ }^{1} *$, Jeong-Chan Ra ${ }^{2}$, Byung-Ki Kim², Yong-Suk Lim ${ }^{1}$, Kyong-Hee Kim${ }^{1}$, Kyong-Eun Lee ${ }^{1}$ \\ ${ }^{1}$ College of Veterinary Medicine, Seoul National University, Seoul 151-742, Korea \\ ${ }^{2} R N L$-Bio, Seoul 151-835, Korea
}

(Received: November 11, 2011; Revised: March 13, 2012; Accepted: March 14, 2012)

\begin{abstract}
Dirofilaria (D.) immitis is an important canine parasitic nematode in dogs. D. immitis parasitizes the right ventricle and pulmonary artery of dogs. An ivermectin and pyrantel pamoate compound (IPPC) was administered to dogs naturally infected with this parasite. IPPC is composed of $68.0,136.0$ and $272.0 \mu \mathrm{g}$ of ivermectin and 57.0, 114.0 and $227.0 \mathrm{mg}$ pyrantel pamoate for small, middle, and large animals. Ivermectin has activity against nematodes and ectoparasites in dogs. Pyrantel pamoate is also effective against nematodes in dogs. Our results showed that this drug combination has good efficacy in D. immitis infected dogs.
\end{abstract}

Keywords : Dirofilaria immitis, ivermectin, ivermectin and pyrantel pamoate compound, pyrantel pamoate

\section{Introduction}

Companion animals are very important to families, as they provide many comfortable, relationships. However, dogs infected with zoonotic parasites can infect humans. Military and police dogs in Korea are frequently infected with parasites, such as Toxocara canis (8.2\%), Toxascaris leonina (2.0\%), and Ancylostoma caninum (17.1\%) [15]. The major parasites in dogs are round-worm (Toxocara canis), whip-worm (Trichuris vulpis), and heart-worm (Dirofilaria immitis) as helminths, Isospora canis and Giardia canis as protozoa, and sarcoptic mites [13]. The prevalence of $D$. immitis in Korea is $2.3 \sim 40.0 \%$ in dogs [2, 5-8, 11, 12].

We conducted a study on the anti-parasitic efficacy and safety of an ivermectin and pyrantel pamoate compound (IPPC) against D. immitis in dogs. After the anti-parasitic activities of IPPC were evaluated in stray dogs, they were re-evaluated in dogs that presented at the private animal clinics.

\section{Materials and Methods}

Animals and feed

The experimental animals were companion animal dogs and stray dogs infected with D. immitis. All had detectable D. immitis microfilaria. Feed and water were supplied ad libitum.

\section{Drugs and parasites}

The components and dosages of the IPPC were as follows. This experiment used the drug formulation of $136.0 \mu \mathrm{g}$ of ivermectin and $114.0 \mathrm{mg}$ of pyrantel pamoate in 1 tablet for medium-sized animals and the $\mathrm{H}$ drug as control drug. For small animals, the effective components of IPPC are $68.0 \mu \mathrm{g}$ of ivermectin and $57.0 \mathrm{mg}$ of pyrantel pamoate in 1 tablet. And for large animals, those are $272.0 \mu \mathrm{g}$ of ivermectin and $227.0 \mathrm{mg}$ of pyrantel pamoate in 1 tablet. The drugs were evaluated for anti-parasitic activity against $D$. immitis in the stray dogs and the companion animal dogs from private animal clinics.

\section{Methods}

After D. immitis microfilaria verified in stray dogs and dogs from private animal clinics, the infected dogs were used in the following experiment. The experimental groups and investigated items are shown in Table 1.

\section{Experimental groups}

Forty-five dogs infected with $D$. immitis were divided

\footnotetext{
*Corresponding author

Tel: +82-2-880-1267, Fax: +82-2-888-0659

E-mail: younhj@snu.ac.kr
} 
Table 1. Experimental groups and items investigated to evaluate the anti-parasitic activities of ivermectin and pyrantel pamoate compound (IPPC) against Dirofilaria immitis

\begin{tabular}{|c|c|c|c|c|c|c|}
\hline \multirow{3}{*}{ Groups } & \multirow{3}{*}{ No. of animals } & \multirow{3}{*}{ Replication } & \multirow{3}{*}{ Treatment } & \multicolumn{3}{|c|}{ Investigated items } \\
\hline & & & & \multicolumn{2}{|c|}{ Reduction rates of larva } & \multirow{2}{*}{ Side effects } \\
\hline & & & & 2 weeks & 4 weeks & \\
\hline Infected control & 5 & 3 & $\mathrm{~N}$ & $1.6(0.0)$ & $0.0(0.0)$ & No \\
\hline $\mathrm{A}$ & 5 & 3 & $\mathrm{Y}$ & $77.7(46.7)$ & $97.7(86.7)$ & No \\
\hline $\mathrm{B}$ & 5 & 3 & $\mathrm{Y}$ & $75.0(46.7)$ & $93.5(80.0)$ & No \\
\hline Total & & & & & & \\
\hline \multirow{2}{*}{ Groups } & \multirow{2}{*}{ Items } & \multicolumn{5}{|c|}{ No of microfilariae (Weeks after treatment) } \\
\hline & & \multicolumn{2}{|c|}{0} & \multicolumn{2}{|l|}{2} & 4 \\
\hline Control & Total & \multicolumn{2}{|c|}{$124(15 / 15)$} & \multicolumn{2}{|l|}{$122(15 / 15)$} & $124(15 / 15)$ \\
\hline Control & Mean & \multicolumn{2}{|c|}{8.27} & \multicolumn{2}{|l|}{8.13} & 8.27 \\
\hline Control & SD & \multicolumn{2}{|c|}{5.36} & \multicolumn{2}{|l|}{3.55} & 4.71 \\
\hline IPPC & Total & \multicolumn{2}{|c|}{$130(15 / 15)$} & \multicolumn{2}{|l|}{$29(8 / 15)$} & $3(2 / 15)$ \\
\hline A & Mean & \multicolumn{2}{|c|}{8.67} & \multicolumn{2}{|l|}{1.93} & 0.20 \\
\hline $\mathbf{A}$ & SD & \multicolumn{2}{|c|}{4.47} & \multicolumn{2}{|l|}{2.12} & 0.56 \\
\hline $\mathbf{H}$ & Total & \multicolumn{2}{|c|}{$108(15 / 15)$} & \multicolumn{2}{|l|}{$27(8 / 15)$} & $7(3 / 15)$ \\
\hline B & Mean & \multicolumn{2}{|c|}{7.20} & \multicolumn{2}{|l|}{1.80} & 0.47 \\
\hline B & SD & \multicolumn{2}{|c|}{3.43} & 1.90 & & 0.99 \\
\hline
\end{tabular}

A: IPPC, B: H control drug.

Table 2. Experimental groups and items investigated to evaluate the anti-parasitic activities of IPPC against Dirofilaria immitis in a private animal hospital

\begin{tabular}{|c|c|c|c|c|c|}
\hline \multirow{3}{*}{ Groups } & \multirow{3}{*}{ No. of animals } & \multirow{3}{*}{ Treatment } & \multicolumn{3}{|c|}{ Investigated items } \\
\hline & & & \multicolumn{2}{|c|}{ Reduction rates of microfilaria in blood } & \multirow{2}{*}{ Symptoms } \\
\hline & & & 2 weeks & 4 weeks & \\
\hline Infected control & 10 & $\mathrm{~N}$ & $31.7(0.0)$ & $5.0(0.0)$ & No \\
\hline RNL drug & 10 & $\mathrm{Y}$ & $88.6(70.0)$ & $98.2(90.0)$ & No \\
\hline Total & 20 & & & & \\
\hline \multirow{2}{*}{ Groups } & \multirow{2}{*}{ Items } & \multicolumn{4}{|c|}{ No of microfilaria (Weeks after treatment) } \\
\hline & & & & 2 & 4 \\
\hline \multirow{3}{*}{ Control } & Total & \multicolumn{2}{|c|}{$120(10 / 10)$} & $82(10 / 10)$ & $114(10 / 10)$ \\
\hline & Mean & \multicolumn{2}{|c|}{12} & 8.2 & 11.4 \\
\hline & SD & \multicolumn{2}{|c|}{6.60} & 4.89 & 5.60 \\
\hline \multirow{3}{*}{ IPPC } & Total & \multicolumn{2}{|c|}{$114(10 / 10)$} & $13(3 / 10)$ & $2(1 / 10)$ \\
\hline & Mean & \multicolumn{2}{|c|}{11.4} & 1.3 & 0.2 \\
\hline & SD & \multicolumn{2}{|c|}{6.93} & 2.21 & 0.63 \\
\hline
\end{tabular}

into three groups, such as IPPC (1D, 2D and 4D) treated groups, a control drug $(\mathrm{H})$ group and an infected control group (Table 1). Twenty dogs from private animal clinics were selected and also used in the experiment. One group compromised the control group and the other group was the IPPC-treated group (Table 2).

\section{Investigated items}

D. immitis microfilarial infections were investigated in the peripheral blood at $0,1,2$, and 4 weeks before and after treatment.

\section{Statistic analysis}

We used Student's $t$ test and SigmaPlot software (ver. 
5.0, Jandel Scientific, USA) to compare the group results.

\section{Results}

Anti-parasitic efficacy of IPPC against $D$. immitis The larval reduction rate in the IPPC-treated group was $77.7 \%$, and it was $75.0 \%$ in the $\mathrm{H}$ control group at 2 weeks post treatment. The individual larval reduction rate of IPPC treated and $\mathrm{H}$ groups was $46.7 \%$. The larval reduction rate in the IPPC-treated group was $97.7 \%$, and it was $93.5 \%$ in the $\mathrm{H}$ control group at 4 weeks after treatment. The individual larval reduction rates in the IPPC-treated and $\mathrm{H}$ control groups were 86.7 and $80.0 \%$, respectively (Table 1).

The anti-parasitic activities of IPPC against $D$. immitis

The microfilarial reduction rate of $D$. immitis in blood was $88.6 \%$ in the IPPC-treated group. The individual microfilarial reduction rate of $D$. immitis in the blood was $70.0 \%$ in the IPPC-treated group at 2 weeks after treatment. The microfilarial reduction rate of $D$. immitis in the blood was $98.2 \%$ in the IPPC-treated group at 4 weeks after treatment. The individual microfilarial reduction rate of $D$. immitis in the blood was $90.0 \%$ in the IPPC-treated group at 4 weeks after treatment (Table 2).

\section{Discussion}

The major canine parasites are round-worm (Toxocara canis), whip-worm (Trichuris vulpis), and heart-worm (D. immitis), protozoa-such as Isospora canis and Giardia canis, and arthropods-mites [13]. In this experiment, the anti-parasitic activity of IPPC was evaluated against $D$. immitis.

Clark et al. [3] reported that the anti-parasitic activity of ivermectin ( $6 \mathrm{mg} / \mathrm{kg}$ body weight) and pyrantel pamoate ( $5 \mathrm{mg}$ active pyrantel $/ \mathrm{kg}$ ) supplied in a beef-based chewable formulation was $100 \%$ against larvae of $D$. immitis. McCall et al. [9] reported that the anti-parasitic reduction rates of ivermectin and milbemycin were 97.7 and $41.4 \%$ against $D$. immitis, respectively. Clemence et al. [4] found that ivermectin (Avermectin) and selamectin also prevented $100 \%$ of D. immitis infections.

Blagburn et al. [1], Rawlings et al. [10], and Takahashi et al. [14] reported the anti-dirofilarial drug, such as ivermectin and milbemycin.

The anti-parasitic activity of IPPC that we found was similar as that determined by other researchers for drugs such as ivermectin and pyrantel pamoate, and ivermectin, milbemycin, and selamectin.

\section{Aknowledgments}

This work was supported by Korean Research Foundation Grant (KRF-2006-005-J02902).

\section{References}

1. Blagburn BL, Dillon AR, Arther RG, Butler JM, Newton JC. Comparative efficacy of four commercially available heartworm preventive products against the MP3 laboratory strain of Dirofilaria immitis. Vet Parasitol 2011, 176, 189-194.

2. Byeon KH, Kim BJ, Kim SM, Yu HS, Jeong HJ, Ock MS. A serological survey of Dirofilaria immitis infection in pet dogs of Busan, Korea, and effects of chemoprophylaxis. Korean J Parasitol 2007, 45, 27-32.

3. Clark JN, Daurio CP, Plue RE, Wallace DH, Longhofer SL. Efficacy of ivermectin and pyrantel pamoate combined in a chewable formulation against heartworm, hookworm, and ascarid infections in dogs. Am J Vet Res 1992, 53, 517-520.

4. Clemence RG, Sarasola P, Genchi C, Smith DG, Shanks DJ, Jernigan AD, Rowan TG. Efficacy of selamectin in the prevention of adult heartworm (Dirofilaria immitis) infection in dogs in northern Italy. Vet Parasitol 2000, 91, 251-258.

5. Kim YH, Huh S. Prevalence of Toxocara canis, Toxascaris leonina and Dirofilaria immitis in dogs in Chuncheon, Korea (2004). Korean J Parasitol 2005, 43, 65-67.

6. Lee JC, Lee CY, Shin SS, Lee CG. A survey of canine heartworm infections among German shepherds in South Korea. Korean J Parasitol 1996, 34, 225-231.

7. Lim S, Irwin PJ, Lee S, Oh M, Ahn K, Myung B, Shin S. Comparison of selected canine vector-borne diseases between urban animal shelter and rural hunting dogs in Korea. Parasit Vectors 2010, 3, 32.

8. Liu J, Song KH, Lee SE, Lee JY, Lee JI, Hayasaki M, You MJ, Kim DH. Serological and molecular survey of Dirofilaria immitis infection in stray cats in Gyunggi province, South Korea. Vet Parasitol 2005, 130, 125-129.

9. McCall JW, McTier TL, Ryan WG, Gross SJ, Soll 
MD. Evaluation of ivermectin and milbemycin oxime efficacy against Dirofilaria immitis infections of three and four months' duration in dogs. Am J Vet Res 1996, 57, 1189-1192.

10. Rawlings CA, Bowman DD, Howerth EW, Stansfield DG, Legg W, Luempert LG. Response of dogs treated with ivermectin or milbemycin starting at various intervals after Dirofilaria immitis infection. Vet Ther 2001, 2, 193-207.

11. Song KH, Lee SE, Hayasaki M, Shiramizu K, Kim DH, Cho KW. Seroprevalence of canine dirofilariosis in South Korea. Vet Parasitol 2003, 114, 231-236.

12. Song KH, Park JE, Lee DH, Lee SH, Shin HJ. Serological update and molecular characterization of
Dirofilaria immitis in dogs, South Korea. Res Vet Sci 2010, 88, 467-469.

13. Soulsby EJL. Helminths, Arthropods and Protozoa of Domesticated Animals. 6th ed. pp. 160, 294-297, 319, 504-507, 595, 641, Bailliere Tindall, London, 1968.

14. Takahashi A, Yamada K, Kishimoto M, Shimizu J, Maeda R. Computed tomography (CT) observation of pulmonary emboli caused by long-term administration of ivermectin in dogs experimentally infected with heartworms. Vet Parasitol 2008, 155, 242-248.

15. Youn HJ, Hong KO, Lee BC, Oh HG. Prevalence of intestinal parasites in dogs and its control in Korea. Korean J Vet Public Health 1995, 19, 257-261. 